\title{
Liver-Metabolizing Genes and Their Relationship to the Performance of Elite Spanish Male Endurance Athletes; a Prospective Transversal Study
}

\author{
David Varillas Delgado ${ }^{1 *}$ D, Juan José Tellería Orriols² and Carlos Martín Saborido ${ }^{3}$
}

\begin{abstract}
Background: The genetic profile that is needed to define an endurance athlete has been studied during recent years. The main objective of this work is to approach for the first time the study of genetic variants in livermetabolizing genes and their role in endurance performance by comparing the allelic and genotypic frequencies in elite endurance athletes to the non-athlete population.

Methods: Genotypic and allelic frequencies were determined in 123 elite endurance athletes (75 professional road cyclists and 48 endurance elite runners) and 122 male non-athlete subjects (sedentary). Genotyping of cytochrome P450 family 2 subfamily D member 6 (CYP2D6 rs3892097), glutathione-S transferase mu isoform 1 (GSTM1), glutathione S-transferase pi (GSTP rs1695) and glutathione S-transferase theta (GSTT) genes was performed by polymerase chain reaction (PCR). The combination of the polymorphisms for the "optimal" polygenic profile has been quantified using the genotype score (GS).
\end{abstract}

Results: Statistical differences were found in the genetic distributions between elite endurance athletes and nonathletes in CYP2D6 $(p<0.001)$ and GSTT $(p=0.014)$ genes. The binary logistic regression model showed a favourable OR (odds ratio) of being an elite endurance runner against a professional road cyclist (OR: 2.403, 95\% Cl: $1.213-4.760(p=0.002))$ in the polymorphisms studied.

Conclusions: Genotypic distribution of liver-metabolizing genes in elite endurance athletes is different to nonathlete subjects, with a favourable gene profile in elite endurance athletes in terms of detoxification capacity.

Keywords: Physical endurance, Performance, Sports, CYP2D6, Cytochrome p 450, Glutathione transferases

\section{Key Points}

- This is the first study that shows that the genetic profile of liver-metabolizing genes in elite endurance athletes (professional cyclists and endurance elite runners) is different from the non-athlete population.

- There is an implication of an "optimal" genetic profile in liver-metabolizing genes in systemic recovery from

\footnotetext{
*Correspondence: david.varillas@ufv.es

'Elite and High-Performance Athletes Research Group, Research Unit, Faculty of Medicine, Universidad Francisco de Vitoria, Pozuelo de Alarcón, Madrid, Spain

Full list of author information is available at the end of the article
}

prolonged continuous efforts in this type of endurance sport, favouring sporting performance.

- Elite endurance runners appear to have a more optimal genetic profile in liver-metabolizing genes than professional cyclists.

\section{Background}

The liver performs a variety of unique functions essential for the preservation of homeostasis, including glucose and lipid metabolism, xenobiotic detoxification, and serum protein synthesis. Most of these roles are performed by the hepatocyte, a quiescent and highly differentiated cell expressing a complement of enabling genes $[1,2]$. The liver's central position in systemic metabolism implies a 
prominent exposure to noxious stimuli derived from environmental toxicants, alcohol, viruses, and dietary habits, the principal causes of liver disease [3].

The combined influence of several genetic variants, each with a significant contribution, as well as the complex interaction of genetic variants, can help to explain individual variations in the human endurance performance. A wide variety of studies find genetic variants that have influence on athletic performance in elite athletes, in running [4-6], soccer [7], triathlon [8], or power efforts $[9,10]$, finding new candidate genes year by year [11]. Several studies show numerous types of livermetabolizing genes, referring to their help in the systemic detoxification of drugs and potentially harmful chemicals and cancer inducers [12-16].

The liver is the main organ of cleaning these harmful endogenous products [17], and one of the most striking features that characterize endurance athletes is their faster systemic recovery from continuous efforts, providing improvement in their performance $[18,19]$. The probability of a perfect polygenic endurance profile has been previously determined [20], showing the influence of genetic variants in this profile of high sporting performance $[8,21-24]$. Recently, the relationship between GSTP gene polymorphisms with performance in Russian and Polish elite athletes has been verified [25], due to a better elimination of exercise-induced reactive oxygen species (ROS).

One of the most striking features that characterize endurance athletes is their faster systemic recovery from continuous efforts, which is mostly related to nutritional supplements like fruit-derived polyphenol [26], quickabsorption carbohydrates [27], and combinations of carbohydrates and proteins [28], providing endogenous improvement performance. In liver metabolism, the interpretation of serum aminotransferases concentration in athletes should consider the release of aspartate aminotransferase (AST) from muscle and of alanine aminotransferase (ALT), mainly from the liver, being markers that predetermine in blood analysis, the endogenous recovery of these endurance athletes [29]. In this work, we approach for the first time the study of genetic variants in liver-metabolizing genes, such as cytochrome $\mathrm{P} 450$ family 2 subfamily D member 6 (CYP2D6), glutathione$\mathrm{S}$ transferase $\mathrm{mu}$ isoform 1 (GSTM1), glutathione Stransferase pi (GSTP), and glutathione S-transferase theta (GSTT), by comparing the allelic and genotypic frequencies in elite endurance athletes with the nonathlete population.

\section{Methods}

\subsection{Study Population}

The studied population comprised 123 elite endurance athletes (75 professional road cyclists and 48 elite endurance runners) and 122 male non-athlete subjects (sedentary). Non-athlete subjects and elite endurance athletes were of Spanish Caucasian descent. The sample size of the group of endurance elite runners was limited, because in Spain, there is not a high enough number of these athletes who have an elite status compared with the number of professional cyclists. All the elite runners had validated high level and elite sports records in endurance competitions: five athletes ran below $2 \mathrm{~h} 10 \mathrm{~min}$ in marathon, 12 athletes below $1 \mathrm{~h} 03 \mathrm{~min}$ in halfmarathon, and the remaining 31 athletes in competitions of $10,000 \mathrm{~m}$ and $5000 \mathrm{~m}$ ran below $30 \mathrm{~min}$ and $14 \mathrm{~min}$, respectively. The athletes participated in marathon or half-marathon of World Championships and/or in 10, $000 \mathrm{~m}$ and $5000 \mathrm{~m}$ runs in the European Championships or Cross-Country World and European Championships. Some of the athletes achieved finalist positions in the marathon and the 10,000 $\mathrm{m}$ in the European Championships, with gold and silver medals in the Cross-Country European Championship, representing Spain. The professional cyclists had participated in the Union Cycliste Internationale (UCI) World-Tour events, including Grand Tours, classic cycle races, other one-day races or stage races (often in all of them). Many of them reached one of the top five positions in endurance competitions: Tour de France, Giro d'Italia, and Vuelta a España.

Both runners and cyclists were males, due to the small number of high-level female athletes in Spain who met the inclusion criteria. The non-athlete subjects were males matched by age to athletes; they were not smokers, nor did they suffer from chronic or acute illnesses at the time of sampling.

Informed consent of all the participants in the study was obtained. The protocol of the study was approved by the Committee of Institutional Ethics (University of Valladolid) and agreed with the Declaration of Helsinki for Human Research of 1974 (last modified in 2000).

\subsection{Genotypes}

\subsubsection{Target Genes}

In order to investigate the role of liver-metabolizing gene variants in the systemic recovery and cleaning of toxic products produced by training and competition in endurance elite sports, the following functional polymorphisms were genotyped in target genes:

c.506-1G>A polymorphism former 1846G $>$ A CYP2D6 gene (location: 22q13.1) generates a change in the canonical sequence at the 3 ' end of intron 3 . This mutation prevents the splicing of the intron 3 exon 4 junction of the mRNA and codes and inactive protein [30], showing a deficiency of several detoxification enzymes that increase the risk for head and neck squamous cell carcinoma in alcohol- and tobacco-exposed individuals [31]. 
"Null"polymorphism of the GSTM1 gene (location: 1p13.3). This null polymorphism causes the reduction of the detoxification capacity of aromatic hydrocarbons [32, 33] and has been related to predisposition to different diseases, such as liver cancer [34], high risk in patients with clear cell renal cell carcinoma (cRCC) [35], and cardiovascular [36] and respiratory diseases [37, 38].

p.Ile105Val polymorphism of the GSTP gene (location: 11q13). The Isoleucine 105 form exhibited lower catalytic activity towards several carcinogenic diol epoxides as compared with the valine 105 form [39]. Individuals with the GST P1 valine allele showed a significantly higher level of DNA adducts [40]. This decrease in GSTP enzyme activity has been shown to increase the risk of several tumours, like brain [41], myeloid leukaemia [42], lymphomas [43], and gastric cancer [44].

GSTT gene (location: 22q11.23) also has a functional (GSTT*1) and a non-functional allele (GSTT*0). The GSTT can detoxify smaller reactive hydrocarbons, such as ethylene oxide and diepoxy butane. The null genotype of GSTT was reported to be associated with an increased risk of bladder cancer, lung cancer, and myelodysplastic syndrome [45].

\subsubsection{Deoxyribonucleic Acid Extraction and Genotyping}

Nucleic Acid Purification Genomic DNA was obtained from ethylenediaminetetraacetic acid (EDTA) anticoagulated blood samples according to standard phenolchloroform procedures, followed by precipitation with ethanol.

Genotyping GSTM1 and GSTT genotyping were carried out by direct PCR amplification and subsequent agarose gel electrophoresis, as previously described [32, 33, 46, 47]. CYP2D6 and GSTP polymorphisms were genotyped by polymerase chain reaction (PCR) amplification, followed by specific restriction fragment analysis in $2 \%$ agarose gel, as previously described [30, 39]. All PCR reactions were carried out in $20 \mu \mathrm{l}$ of the total volume, being DNA concentrations between 125 and $250 \mu \mathrm{gr}$. The primers sequence at target genes and PCR conditions are shown in Table 1 and Table 2.

\section{3 "Optimal" Polygenic Profile for Endurance}

\section{Performance in the Spanish Population (Caucasian)}

The probability that an individual bears the "optimal" genotype for each of the four polymorphisms was calculated based on the typical frequency of each genotype observed in Spanish people (Caucasian descent for the population of $\geq 3$ generations) [45, 48] (Table 3). An "optimal" GS of 2 was scored for the polymorphisms of the CYP2D6 and GSTP genes and an "optimal" GS was scored 1 for the polymorphisms of the GSTM and
Table 1 Primers sequence at target genes

\begin{tabular}{lll}
\hline CYP2D6 & Forward & 5'-GCCTTCGCCAACCACTCCG-3' \\
& Reverse & 5'-AAATCCTGCTCTTCCGACGC-3' \\
GSTM1 & A & 5'-CGCCATCTTGTGCTACATTGCCCG-3' \\
& B & 5'-ATCTTCTCCTCTTCTGTCTC-3' \\
& C & 5'-TTCTGGATTGTAGCAGATCA-3' \\
GSTP & Forward & 5'-ACCCCAGGGCTCTATGGGAA-3' \\
& Reverse & 5'-TGAGGGCACAAGCCCCT-3' \\
GSTT & Forward & 5'-TTCCTTACTGGTCCTCACATCTC-3' \\
& Reverse & 5'-TCACCGGATCATGGCCAGCA-3' \\
\hline
\end{tabular}

GSTT genes. A scale was made with the estimated probability of having a "perfect" genetic profile, considering the number of polymorphisms included in the entire profile [24].

Based on the typical frequencies observed from the "optimal" genotypes, a scale was generated, estimating the probability of possessing a "perfect" genetic profile, having taken into account the polymorphisms included [24].

\subsection{Polygenic Potential for the Endurance Performance of the Spanish Population}

The combined influence of the four polymorphisms studied was calculated, following the procedure of Williams and Folland [20]. First, each genotype was scored

Table 2 PCR conditions

\begin{tabular}{|c|c|c|c|}
\hline \multirow[t]{5}{*}{ CYP2D6 } & & Initial denaturation & $94^{\circ} 5 \mathrm{~min}$ \\
\hline & \multirow[t]{4}{*}{$\times 30$ cycles } & Denaturation & $94^{\circ} 1 \mathrm{~min}$ \\
\hline & & Annealing & $60^{\circ} 1 \mathrm{~min}$ \\
\hline & & Extension & $72^{\circ} 2 \min$ \\
\hline & & Final extension & $72^{\circ} 5 \min$ \\
\hline \multirow[t]{5}{*}{ GSTM1 } & & Initial denaturation & $95^{\circ} 5 \mathrm{~min}$ \\
\hline & \multirow[t]{4}{*}{$\times 40$ cycles } & Denaturation & $94^{\circ} 30 \mathrm{sec}$ \\
\hline & & Annealing & $58^{\circ} 30 \mathrm{sec}$ \\
\hline & & Extension & $72^{\circ} 45 \mathrm{sec}$ \\
\hline & & Final extension & $72^{\circ} 8 \min$ \\
\hline \multirow[t]{5}{*}{ GSTP } & & Initial denaturation & $94^{\circ} 5 \min$ \\
\hline & \multirow[t]{4}{*}{$\times 35$ cycles } & Denaturation & $94^{\circ} 30 \mathrm{sec}$ \\
\hline & & Annealing & $55^{\circ} 30 \mathrm{sec}$ \\
\hline & & Extension & $72^{\circ} 30 \mathrm{sec}$ \\
\hline & & Final extension & $72^{\circ} 5 \mathrm{~min}$ \\
\hline \multirow[t]{5}{*}{ GSTT } & & Initial denaturation & $95^{\circ} 5 \mathrm{~min}$ \\
\hline & \multirow[t]{4}{*}{$\times 30$ cycles } & Denaturation & $95^{\circ} 1 \mathrm{~min}$ \\
\hline & & Annealing & $60^{\circ} 1 \mathrm{~min}$ \\
\hline & & Extension & $72^{\circ} 1 \mathrm{~min}$ \\
\hline & & Final extension & $72^{\circ} 10 \mathrm{~min}$ \\
\hline
\end{tabular}


Table 3 Genotyping frequency in the Spanish population and elite endurance athletes

\begin{tabular}{|c|c|c|c|c|c|}
\hline Symbol & Gene & Polymorphism & $\begin{array}{l}\text { Genotypes ( } 2 \text { or } 1 \text { = "optimal" } \\
\text { endurance genotype) }\end{array}$ & $\begin{array}{l}\text { Frequency in } \\
\text { Spanish } \\
\text { population } \\
(\%)\left({ }^{*}\right)\end{array}$ & $\begin{array}{l}\text { Frequency in } \\
\text { Spanish elite } \\
\text { endurance } \\
\text { athletes (\%) }\end{array}$ \\
\hline CYP2D6 & Cytochrome P450 family 2 subfamily D member 6 & c.506-1G>A & $0=A A-1=G A-2=G G$ & $4-27-69$ & $1-14-85$ \\
\hline GSTM1 & Glutathione S-transferase mu & Functional(+)/null(-) & $0=--1=+$ & $82-18$ & $71-29$ \\
\hline GSTP & Glutathione S-transferase pi & lle(l)105Val(V) & $0=\mathrm{GG}-1=\mathrm{GA}-2=\mathrm{AA}$ & $41-45-14$ & $6-31-63$ \\
\hline GSTT & Glutathione S-transferase tetha & Functional (+)/null(-) & $0=--1=+$ & $64-36$ & $28-72$ \\
\hline
\end{tabular}

$(*)$ www.ensembl.org

within each polymorphism (Table 3). A genotype score (GS) of 2 or 1 was assigned to the "optimal" or preferable endurance genotype, while a GS of 0 was assigned to the less optimal genotype [49]. Secondly, the GSs of all genotypes $\left(\mathrm{GS}_{\mathrm{CYP} 2 \mathrm{D} 6}+\mathrm{GS}_{\mathrm{GSTM} 1}+\mathrm{GS}_{\mathrm{GSTP}}+\mathrm{GS}_{\mathrm{GSTT}}\right)$ were added, and finally the score was transformed to a $0-100$ scale to facilitate interpretation, namely the total genotype score (TGS), as follows:

$T G S=(100 / 6) \times\left(G S_{C Y P 2 D 6}+G S_{G S T M 1}+G S_{G S T P}+\right.$ $\left.G S_{G S T T}\right)$

The maximum score for CYP2D6 and GSTP was 2 and for GSTM1 and GSTT it was 1. Thus 6 is the maximum total sum of all GSs, and therefore the "optimal" or preferable genotypic profile. As indicated [20], a TGS of 100 represents a "perfect" profile and a TGS of 0 should be the "worst" possible profile for endurance sports when all GSs have a score of 0. Finally, the TGSs' distribution between elite endurance athletes and nonathletes was assessed.

\subsection{Polygenic Potential for Endurance Performance in the Spanish Control Population and High-Level Athletes}

A polygenic profile was calculated for each endurance elite athlete and non-athlete subject, as described, in order to analyse both the nature of the TGS distribution in a highly selected group of Spanish endurance athletes, and the differences between these and the subgroups of cyclists and runners vs. non-athletes.

\subsection{Statistical Analysis}

The statistical average and kurtosis were calculated using Statistical Package for the Social Sciences (SPSS), v.20.0 for Windows (IBM Corp. Released 2012. IBM SPSS Statistics for Windows, Version 20.0. Armonk, NY: IBM Corp). The probability of having an "optimal" endurance genotype for one to four polymorphisms between elite endurance athletes and non-athletics was calculated by using the $\chi^{2}$ test with fixed $\alpha 0.05$. The genotypic frequencies of the polymorphisms in CYP2D6, GSTM1, GSTP, and GSTT genes were compared between elite endurance athletes and non-athletics, using a $\chi^{2}$ test with fixed $\alpha 0.05$.

The ability of TGS to correctly distinguish potential elite endurance athletes from non-athletes $(0=$ non- athlete, $1=$ elite) was assessed using receiver operating characteristic (ROC) curves [50]. With that purpose, the area under the ROC curve (AUC) was calculated with confidence intervals of $95 \%$ (95\% CI). Finally, a binary logistic regression model was used to study the relationship between TGS and the athletic status.

\section{Results}

In the non-athlete population, the mean value of the TGS was 65.706 ( \pm 16.360$)$, statistical kurtosis: -0.182 $( \pm 0.435)$, and in the group of elite endurance athletes it was 73.709 ( \pm 16.531), statistical kurtosis: - 0.096 ( \pm 0.433 ). The mean value of the TGS in professional cyclists was $72.885( \pm 15.445)$ statistical kurtosis: - 0.087 $( \pm 0.548)$, and of endurance elite runners it was 74.996 $( \pm 18.193)$, statistical kurtosis: $-0.052( \pm 0.674)$. The distributions of TGS frequencies of the 122 non-athletes and 123 elite endurance athletes are represented in Fig. 1. Figure 2 shows the frequency distribution of the TGSs of cyclists and elite runners and the 122 non-athlete subjects.

TGS distribution in elite endurance athletes is shifted to the right with respect to non-athletes. Sixteen elite endurance athletes $(13.0 \%)$ and only three non-athletes (2.5\%) exhibited an "optimal" TGS of 100 . The difference in the distribution of TGSs between both groups was statistically significant $(p<0.001)$ (Table 4$)$.

ROC analysis showed significant discriminatory accuracy of TGSs in the identification of elite endurance athletes $(\mathrm{AUC}=0.629 ; 95 \% \mathrm{CI}: 0.559-0.698)(p<0.001)$ $($ sensitivity $=0.488$, specificity $=0.689)$ (Fig. 3$)$. The corresponding TGS value at this point was 74.995. Binary logistic regression analysis showed that subjects with a higher TGS of this value (74.995) had an odds ratio (OR) of 1.171 (95\% CI: $0.816-1.680(p=0.245)$ ) of being elite endurance athletes, compared to those with a TGS below this value. The endurance elite runners showed an OR at the cut-off point in comparison to the non-athlete population of 2.403 (95\% CI: 1.213-4.760) $(p=0.002)$ ) and professional cyclists, in comparison to non-athlete subjects, had an OR of 1.029 (95\% CI: $0.735-1.442)(p=0.462)$ ).

Genotype distribution of liver-metabolizing genes in the elite endurance athletes' group when compared with 


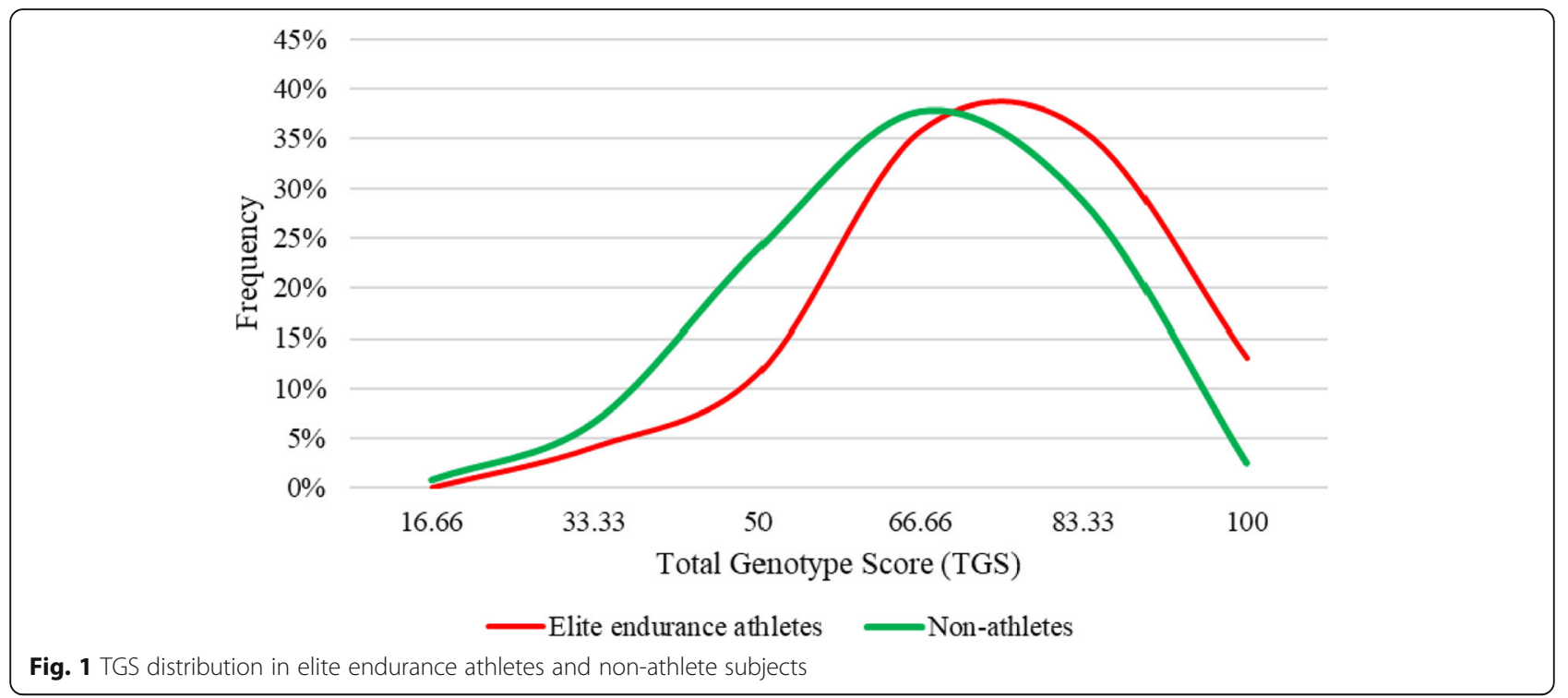

the non-athlete population was statistically significant for CYP2D6 $(p<0.001)$, showing a higher frequency in the "optimal" genotype in athletes (G/G 85.36\%) than the non-athlete population (G/G 62.30\%); in GSTT "optimal" polymorphism, the frequency was higher in elite endurance athletes than non-athletes' $(p=0.014)$ (Table 5). Between both groups of elite endurance athletes (cyclists and runners), statistically significant results were found in CYP2D6 $(p=0.002)$ and GSTT genes ( $\mathrm{p}$ $=0.049$ ) compared with non-athletes (Table 6).

\section{Discussion}

A great variety of external factors influence an individual's ability to succeed in sport; however, genetics may play an important role in determining sporting achievement, so creating individualized training programmes based on genetic predispositions is important, as is identifying athletes who need an adapted training routine to improve their performance and to account for individual susceptibility to injury $[51,52]$.

For many years, genes with allelic variants have been identified as predisposing individuals to elite endurance, including Actinin Alpha 3 (ACTN3) [9] and Angiotensin Converting Enzyme (ACE) [53]. A recent study of a cohort of Caucasian elite athletes, from $1500 \mathrm{~m}$ runners to marathon runners, showed no differences in endurance running times related to these polymorphisms in ACE and ACTN3 genes previously described [54]. This study presented 698 Caucasian elite athletes with similar performance profile to our sample, found different results

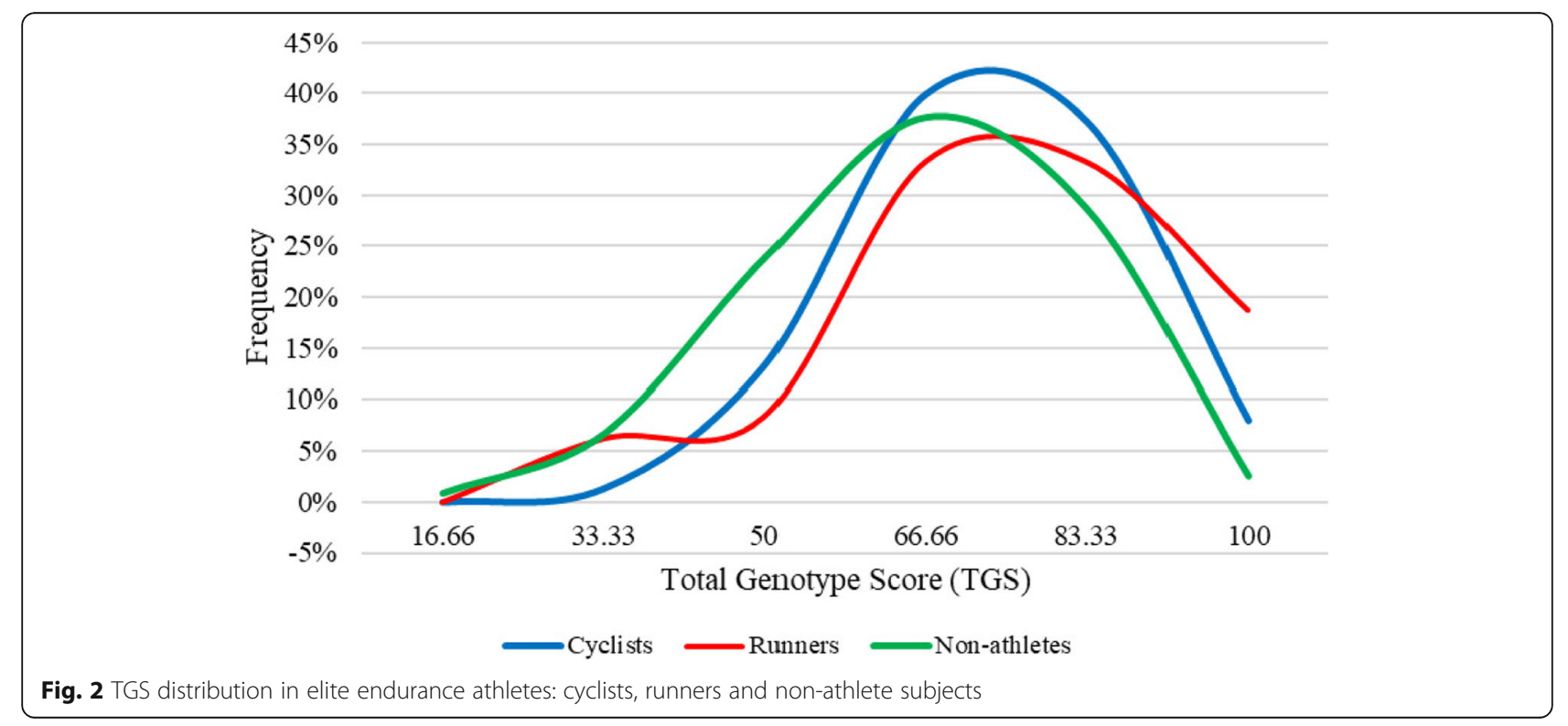


Table 4 Distribution of elite endurance athletes and non-athletes with GS of 0-6 in target genes

\begin{tabular}{lll}
\hline Number of accumulated genotypes in an "optimal" GS individual score & $\begin{array}{l}\text { Elite endurance athletes } \\
(n=123)(\text { accumulative \%) }\end{array}$ & $\begin{array}{l}\text { Non-athletes }(n=122) \\
\text { (accumulative \%) }\end{array}$ \\
\hline 0 & $0(0.00 \%)$ & $0(0.00 \%)$ \\
1 & $0(0.00 \%)$ & $1(0.82 \%)$ \\
2 & $5(4.06 \%)$ & $8(7.37 \%)$ \\
3 & $14(15.44 \%)$ & $29(31.14 \%)$ \\
4 & $44(51.22 \%)$ & $46(68.85 \%)$ \\
5 & $44(86.99 \%)$ & $35(97.54 \%)$ \\
6 & $16(100.00 \%)$ & $3(100.00 \%)$ \\
\hline
\end{tabular}

from ours. The results should be corroborated in subsequent studies with the same polymorphisms presented in our elite endurance athletes.

Different pathologic as well as non-pathologic conditions could increase the production of free radicals or drain the antioxidant defence system. Prolonged and intensive exercise is one of the oxidative stress-inducing conditions, via overproduction of reactive oxygen species and reactive nitrogen species.
This oxidative stress in endurance sports and elite athletes is a determinant of performance. It is known that in competitions like cycling, in which the accumulated efforts of several weeks affect the performance, which also happens in endurance elite runners, with their requirement of several weeks of preparation for a world championship, European championship or marathon, this is mainly due to the alteration in the redox-system of the systemic homeostasis and withdrawal of toxic products generated by high oxidative stress [55-57].

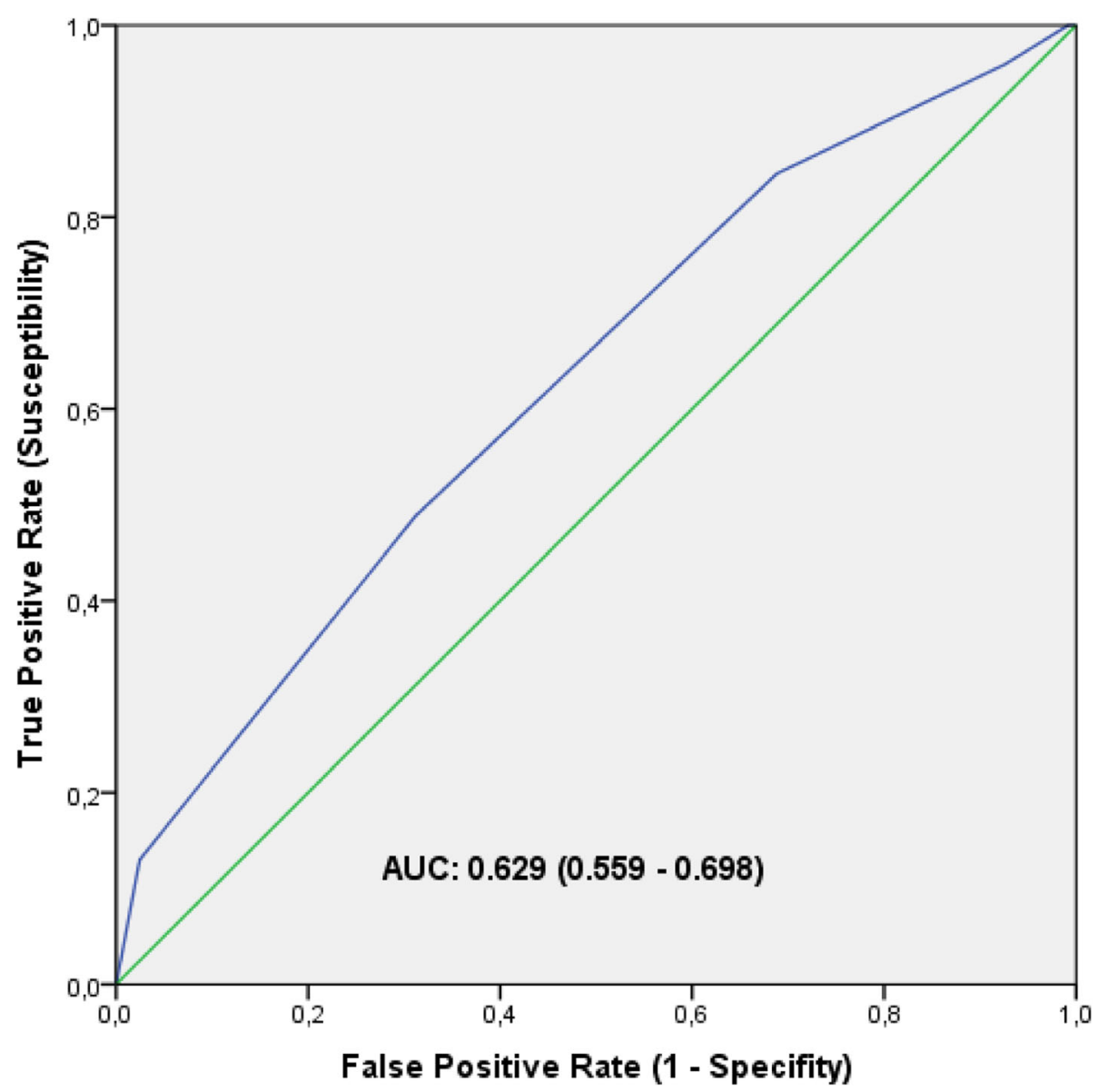

Fig. 3 ROC curve summarizing the ability of TGS to distinguish potential elite endurance athletes from non-athletes 
Table 5 Genotype distribution in elite endurance athletes and non-athletes of liver-metabolizing polymorphisms

\begin{tabular}{cll}
\hline & Elite endurance athletes $(n=123) n(\%)$ & Non-athletes $(n=122) n(\%)$ \\
\hline CYP2D6 & $1(1.66 \%)$ & $2(1.64 \%)$ \\
A/A & $17(13.82 \%)$ & $44(36.06 \%)$ \\
G/A & $105(85.36 \%)$ & $76(62.30 \%)$ \\
G/G & & \\
GSTM1 & $36(29.27 \%)$ & $45(36.88 \%)$ \\
+ & $87(70.73 \%)$ & $77(63.12 \%)$ \\
- & & \\
GSTP & $8(6.51 \%)$ & $13(10.65 \%)$ \\
G/G & $38(30.89 \%)$ & $48(39.35 \%)$ \\
G/A & $77(62.60 \%)$ & $61(50 \%)$ \\
A/A & & \\
GSTT & $89(72.36 \%)$ & $70(57.38 \%)$ \\
+ & $34(27.64 \%)$ & $52(42.62 \%)$ \\
\hline
\end{tabular}

There is recent evidence that diet has an important role in helping to reduce this oxidative stress by ingesting carbohydrate-rich diets $[58,59]$ and lipids $[60]$ in longdistance sports, especially cycling [61, 62] and elite running $[63,64]$. However, there are still insufficient studies that consider the genetic heritage of individuals and especially high-performance athletes in the systemic cleansing of oxidative stress. Only a recently published pilot study by Al-Khelaifi et al. [65] provides evidence that high-power and high-endurance athletes exhibit a distinct metabolic profile, defined by a genetic pool, that reflects steroid biosynthesis, fatty acid metabolism, oxidative stress, and energy-related metabolites; this will become a broad field of study in the coming years to ascertain the systemic recovery of high performance athletes. Al-Khelaifi et al.'s study analysed 743 metabolites; gamma-glutamyl amino acids were significantly reduced in both high-power and high-endurance athletes compared with moderate counterparts, indicating an active glutathione cycle, the same metabolic pathway that can explain the phenotype of the genotypes showed in this study. To date, the genetic markers and polymorphisms that have been studied on an individual basis have been involved in muscle damage [66], muscular modulation [67-70], and in the immune system of these elite endurance athletes $[71,72]$; these have been necessary studies that have shown that all these polymorphisms must be investigated in order to understand the implications of oxidative stress in a global way.

The enzymatic activity of the proteins coded by the sequences of GSTM1 [73] and GSTP [74, 75] genes has been previously identified as a risk factor in diseases of oxidative stress and is associated with the risk of developing chronic severe ethanol liver damage. On the other side, CYP2D6 is a molecule of the cytochrome P450 superfamily that metabolizes several drugs and endogenous molecules. Its activity has been associated with different oxidative stress-related processes, as mitochondrial respiration [75], liver toxicity [76], or toxicity of reactive metabolites in erythrocytes [77]. This work is the first in this field that shows a pool of polymorphisms in liver-metabolizing genes, such as glutathione transferases and the cytochrome P450 family 2 subfamily D member 6 (which influence systemic recovery by the hepatic cleansing of endogenous toxic products generated by intense exercise), between the non-athletic population and elite endurance athletes. A recent study shows the relationship between GSTP polymorphism in Russian and Polish athletes [25], showing statistical data among highperformance athletes and the non-athlete population. But nevertheless, in this study, no differences have been found between athletes and the non-athlete population

Table 6 Genotype frequencies in liver metabolizers between elite endurance athletes (cyclist, runners) and non-athletes

\begin{tabular}{|c|c|c|c|c|c|c|c|c|}
\hline & & \multicolumn{4}{|c|}{ CYP2D6 genotype } & \multicolumn{3}{|c|}{ GSTT genotype } \\
\hline & & $\overline{G G}$ & GA & $A A$ & $p$ value & + & - & $p$ value \\
\hline \multirow[t]{3}{*}{ Elite endurance athletes } & Cyclists & $63(84.00 \%)$ & $11(14.66 \%)$ & $1(1.33 \%)$ & 0.002 & $54(72.00 \%)$ & $21(28.00 \%)$ & 0.049 \\
\hline & Runners & $42(87.50 \%)$ & $6(12.50 \%)$ & $0(0.00 \%)$ & & 35 (72.91\%) & $13(27.09 \%)$ & \\
\hline & Non-athletes & 76 (62.29\%) & $44(36.06 \%)$ & $2(1.64 \%)$ & & $70(57.37 \%)$ & $52(42.63 \%)$ & \\
\hline
\end{tabular}


in the GSTP polymorphism studied, which may be due to sample size (698 athletes in the Zarebska study vs. 122 athletes in this study).

CYP2D6 and GSTT polymorphisms present a genotypic frequency in elite endurance athletes different from the non-athlete population; it is associated with a higher metabolic activity of proteins [30, 45, 46], a fact that predisposes this group to a better metabolic capacity. Differences between the two sub-groups of endurance athletes are not evident, as the frequencies between cyclists and runners are similar, corresponding to a CYP2D6 polymorphism of an "optimal" genotype of $84 \%$ in cyclists and $87.5 \%$ in runners, while null polymorphism in the GSTT gene was "optimal" in 72\% of cyclists as against $72.91 \%$ of runners (Table 6). However, the null genotype of GSTM1 showed more frequently in athletes, needs to be investigated in subsequent studies to verify these Caucasian athletes' frequencies. In turn, it was found that the definition of "optimal" genotypes in the work of Williams and Folland [20] implied that elite endurance athletes have a significantly higher proportion of TGS than the non-athlete population and a lower proportion of not optimal genotypes $(p<0.001)$ (Table 4 ), showing that the liver-metabolizing genes studied presented in the group of elite endurance athletes an "optimal" genotype that was significant in comparison to non-athletes. The endurance elite runners present favourable genetics in these polymorphisms than professional cyclists due to provokes more concentration of oxidative stress biomarkers than cycling [78, 79], using the glutathione (GSH) pathway, corroborated by TGS scores; the endurance elite runners showed an OR at the cut-off point in comparison to the non-athlete population of $2.403(p=0.002)$ and professional cyclists with respect to non-athlete subjects showed an OR of 1.029 $(p=0.462)$.

In this research, the genetic profiles defined by genetic polymorphisms of liver-metabolizing genes in 123 elite endurance athletes were compared with 122 non-athlete males. We decided to include these livermetabolizing genes in the study, since the toxic effects described are similar to those of highperformance sportsmen in continuous efforts, being able to produce the endogenous products as free radicals and peroxides as a decrease in the physical capacity of them. Oxidative stress is the consequence of an impaired balance between free radical production and the endogenous antioxidant protection system. Only four known polymorphisms have been studied, one within each target gene. Another interesting variant within these genes has not been included and constitutes ground for further studies and a better definition about the role of genetic variations in livermetabolizing genes and endurance performance.
In other previous genetic association studies of sportive performance, the ethnic and geographical origins of the athletes included in the studies have been mixed. Our work does not present these limitations, since we have focused on Caucasian Spanish elite endurance athletes' performance, provided by the Spanish Higher Council of Sports (CSD).

For the first time, to the best of our knowledge, the relationship between these polymorphisms in livermetabolizing target genes is shown, leading the capacity of systemic recovery in elite endurance athletes; this is a new type of genetic study, showing a definitive model of the profile in these types of genes that help the capacity of systemic cleansing of ROS produced by the physical effort in this group of subjects in order to understand the multiple and complex mechanisms that define it.

Subsequent studies in relation to genetic profiles and the serum analysis of catabolites for oxidative stress products in elite endurance athletes to determine their ability to clean these products for a return to systemic homeostasis should be carried out in order to corroborate the results shown in this study and to be able to conclude that these genetic markers are predisposed to the metabolizing capacity of toxic waste products induced by high performance endurance.

\section{Conclusions}

It is demonstrated for the first time that genotypic distribution in elite endurance athletes as regards endurance (professional cyclist and elite runners) is different to the non-athlete Caucasian population, there being a favourable gene profile in terms of the detoxification capacity. These results open a new way of study of this genes group to complete the knowledge of oxidative stress and recovery of systemic homeostasis in high performance in endurance sports.

\section{Abbreviations \\ 95\%Cl: Confidence intervals of 95\%; ACE: Angiotensin l-converting enzyme; ACTN3: Actinin alpha 3; ADRB: Adrenergic receptor beta; ALT: Alanine aminotransferase; AST: Aspartate aminotransferase; AUC: Area under the ROC curve; CRCC: Cell renal cell carcinoma; CSD: Spanish Higher Council of Sports; CYP2D6: Cytochrome P450 family 2 subfamily D member 6; \\ DNA: Deoxyribonucleic acid; EDTA: Ethylenediaminetetraacetic acid \\ GS: Genotype score; GSH: Glutathione; GSTM1: Glutathione-S transferase mu isoform 1; GSTP: Glutathione S-transferase pi; GSTT: Glutathione S-transferase theta; OR: Odds ratio; PCR: Polymerase chain reaction; \\ PPARGC1A: Peroxisome proliferator-activated receptor gamma coactivator 1- alpha; ROC: Receiver operating characteristic; ROS: Reactive oxygen species; SPSS: Statistical package for the social sciences; TGS: Total genotype score; UCl: Union cycliste internationale}

\section{Acknowledgements}

The authors appreciate the support of the Spanish Higher Council of Sports (CSD) for the realization of this study and thank Angel Martín Pastor for his invaluable help in collecting high performance athletes for this study. We also thank Félix Gómez (European University, Madrid, Spain) and Jonathan Ruiz (University of Granada, Spain) for their help in conducting the statistical study. Additionally, we appreciate the support of Dra. Maria del Carmen 
Turpin (Francisco de Vitoria University, Madrid, Spain) for the assessment of genetical corrections in the manuscript.

\section{Authors' Contributions}

DVD has carried out the genetic study and recruitment of participants, as well as the statistical study, forming part of his doctoral thesis. JJTO has been the reviewer of the work, helping to search for the genes involved, as well as in the setting up of the study and genetic analysis. CMS has collaborated in the statistics of the work, the conclusions, writing and guiding for its edition, and in the perfection of the methodological aspects, being the senior author. All authors read and approved the final manuscript.

\section{Funding}

The present study has been funded by the Spanish Higher Council of Sports (CSD), through the project "Study and validation of genetic polymorphisms that predict a better performance in endurance sports" (15/UPB10/08).

\section{Availability of Data and Materials}

All data generated or analysed during this study are included in this published article.

\section{Ethics Approval and Consent to Participate}

Informed consent of all the participants in the study was obtained. The protocol of the study was approved by the Committee of Institutional Ethics (University of Valladolid) and agreed with the Declaration of Helsinki for Human Research of 1974 (last modified in 2000).

\section{Consent for Publication}

Not applicable.

\section{Competing Interests}

The authors, David Delgado, Juan Orriols, and Carlos Saborido, declare that they have no competing interests.

\section{Author details \\ ${ }^{1}$ Elite and High-Performance Athletes Research Group, Research Unit, Faculty of Medicine, Universidad Francisco de Vitoria, Pozuelo de Alarcón, Madrid, Spain. ${ }^{2}$ Elite and High-Performance Athletes Research Group, Institute of Biology and Molecular Genetics (IBMG/CSIC), University of Valladolid, Valladolid, Spain. ${ }^{3}$ Fundación San Juan de Dios. Faculty of Health Sciences San Rafael, Nebrija University, Madrid, Spain.}

\section{Received: 18 April 2019 Accepted: 19 November 2019}

Published online: 09 December 2019

\section{References}

1. Elizalde M, Urtasun R, Azkona M, Latasa MU, Goni S, Garcia-Irigoyen O, et al. Splicing regulator SLU7 is essential for maintaining liver homeostasis. J Clin Invest. 2014;124(7):2909-20.

2. Costa RH, Kalinichenko W, Holterman AX, Wang X. Transcription factors in liver development, differentiation, and regeneration. Hepatology. 2003;38(6): 1331-47.

3. Blachier M, Leleu H, Peck-Radosavljevic M, Valla DC, Roudot-Thoraval F. The burden of liver disease in Europe: a review of available epidemiological data. J Hepatol. 2013:58(3):593-608.

4. Ben-Zaken S, Meckel Y, Nemet D, Eliakim A. Genetic score of power-speed and endurance track and field athletes. Scand J Med Sci Sports. 2015;25(2): 166-74.

5. Tucker R, Santos-Concejero J, Collins M. The genetic basis for elite running performance. Br J Sports Med. 2013;47(9):545-9.

6. Drozdovska SB, Dosenko VE, Ahmetov II, llyin VN. The association of gene polymorphisms with athlete status in ukrainians. Biol Sport. 2013;30(3):163-7.

7. Egorova ES, Borisova AV, Mustafina LJ, Arkhipova AA, Gabbasov RT, Druzhevskaya AM, et al. The polygenic profile of Russian football players. J Sports Sci. 2014;32(13):1286-93.

8. Grealy R, Herruer J, Smith CL, Hiller D, Haseler LJ, Griffiths LR. Evaluation of a 7-gene genetic profile for athletic endurance phenotype in ironman championship triathletes. PLoS One. 2015:10(12):e0145171.

9. Eynon N, Hanson ED, Lucia A, Houweling PJ, Garton F, North KN, et al. Genes for elite power and sprint performance: ACTN3 leads the way. Sports Med. 2013;43(9):803-17.
10. Hughes DC, Day SH, Ahmetov II, Williams AG. Genetics of muscle strength and power: polygenic profile similarity limits skeletal muscle performance. J Sports Sci. 2011;29(13):1425-34.

11. Ahmetov II, Egorova ES, Gabdrakhmanova LJ, Fedotovskaya ON. Genes and athletic performance: an update. Med Sport Sci. 2016;61:41-54.

12. Yang $X$, Liu W, Lin $H$, Zeng $H$, Zhang $R$, Pu C, et al. Interaction effects of AFB1 and MC-LR co-exposure with polymorphism of metabolic genes on liver damage: focusing on SLCO1B1 and GSTP1. Sci Rep. 2017;7(1):16164.

13. Schioth HB, Bostrom A, Murphy SK, Erhart W, Hampe J, Moylan C, et al. A targeted analysis reveals relevant shifts in the methylation and transcription of genes responsible for bile acid homeostasis and drug metabolism in non-alcoholic fatty liver disease. BMC Genomics. 2016;17:462.

14. Boso V, Herrero MJ, Buso E, Galan J, Almenar L, Sanchez-Lazaro I, et al. Genotype and allele frequencies of drug-metabolizing enzymes and drug transporter genes affecting immunosuppressants in the Spanish white population. Ther Drug Monit. 2014;36(2):159-68.

15. Krajka-Kuzniak V, Paluszczak J, Szaefer H, Baer-Dubowska W. Betanin, a beetroot component, induces nuclear factor erythroid-2-related factor 2mediated expression of detoxifying/antioxidant enzymes in human liver cell lines. Br J Nutr. 2013;110(12):2138-49.

16. Andrade RJ, Agundez JA, Lucena MI, Martinez C, Cueto R, Garcia-Martin E. Pharmacogenomics in drug induced liver injury. Curr Drug Metab. 2009; 10(9):956-70.

17. Madrigal-Santillan E, Madrigal-Bujaidar E, Alvarez-Gonzalez I, SumayaMartinez MT, Gutierrez-Salinas J, Bautista M, et al. Review of natural products with hepatoprotective effects. World J Gastroenterol. 2014;20(40):14787-804

18. Kubukeli ZN, Noakes TD, Dennis SC. Training techniques to improve endurance exercise performances. Sports Med. 2002;32(8):489-509.

19. Peinado AB, Benito PJ, Barriopedro M, Lorenzo I, Maffulli N, Calderon FJ. Heart rate recovery in elite Spanish male athletes. J Sports Med Phys Fitness. 2014;54(3):264-70

20. Williams AG, Folland JP. Similarity of polygenic profiles limits the potential for elite human physical performance. J Physiol. 2008;586(1):113-21.

21. Loos RJ, Hagberg JM, Perusse L, Roth SM, Sarzynski MA, Wolfarth B, et al. Advances in exercise, fitness, and performance genomics in 2014. Med Sci Sports Exerc. 2015:47(6):1105-12.

22. Santiago C, Ruiz JR, Muniesa CA, Gonzalez-Freire M, Gomez-Gallego F, Lucia A. Does the polygenic profile determine the potential for becoming a world-class athlete? Insights from the sport of rowing. Scand J Med Sci Sports. 2010;20(1):e188-94.

23. Gomez-Gallego F, Ruiz JR, Buxens A, Altmae S, Artieda M, Santiago C, et al. Are elite endurance athletes genetically predisposed to lower disease risk? Physiol Genomics. 2010;41(1):82-90.

24. Ruiz JR, Gomez-Gallego F, Santiago C, Gonzalez-Freire M, Verde Z, Foster C, et al. Is there an optimum endurance polygenic profile? J Physiol. 2009; 587(Pt 7):1527-34

25. Zarebska A, Jastrzebski Z, Ahmetov ZP II, Cieszczyk P, Leonska-Duniec A et al. GSTP1 c.313A>G polymorphism in Russian and Polish athletes. Physiol Genomics. 2017:49(3):127-31.

26. Bowtell J, Kelly V. Fruit-derived polyphenol supplementation for athlete recovery and performance. Sports Med. 2019;49(Suppl 1):3-23.

27. Gonzalez JT, Fuchs CJ, Betts JA, van Loon LJ. Glucose plus fructose ingestion for post-exercise recovery-greater than the sum of its parts? Nutrients. 2017; 30, 9(4). https://doi.org/10.3390/nu9040344.

28. Beelen M, Burke LM, Gibala MJ, van Loon LJ. Nutritional strategies to promote postexercise recovery. Int J Sport Nutr Exerc Metab. 2010;20(6): 515-32.

29. Banfi G, Colombini A, Lombardi G, Lubkowska A. Metabolic markers in sports medicine. Adv Clin Chem. 2012;56:1-54

30. Pindurova E, Zourkova A, Zrustova J, Jurica J, Pavelka A. Alternative reliable method for cytochrome P450 2D6 poor metabolizers genotyping. Mol Biotechnol. 2013:53(1):29-40.

31. Gronau S, Koenig-Greger D, Jerg M, Riechelmann H. Gene polymorphisms in detoxification enzymes as susceptibility factor for head and neck cancer? Otolaryngol Head Neck Surg. 2003;128(5):674-80.

32. Li J, Zhu JF, Zhang W, Liu B, Ma HZ. Relation of GSTM1 polymorphism with leukemia. Zhongguo Shi Yan Xue Ye Xue Za Zhi. 2017;25(2):318-21.

33. Morales E, Sunyer J, Julvez J, Castro-Giner F, Estivill X, Torrent $M$, et al. GSTM1 polymorphisms modify the effect of maternal smoking during pregnancy on cognitive functioning in preschoolers. Int J Epidemiol. 2009; 38(3):690-7. 
34. Liu HZ, Peng J, Peng CY, Yan M, Zheng F. Glutathione S-transferase M1 null genotype and hepatocellular carcinoma susceptibility in China and India: evidence from an updated meta-analysis. Asian Pac J Cancer Prev. 2014; 15(12):4851-6.

35. Coric VM, Simic TP, Pekmezovic TD, Basta-Jovanovic GM, Savic Radojevic AR, Radojevic-Skodric SM, et al. Combined GSTM1-null, GSTT1-active, GSTA1 low-activity and GSTP1-variant genotype is associated with increased risk of clear cell renal cell carcinoma. PLoS One. 2016;11(8):e0160570.

36. Yang M, Zhao J, Xing L, Shi L. Association between GSTM1 null genotype and coronary artery disease risk: a meta-analysis. Med Sci Monit. 2014;20:1550-5.

37. Wu CC, Ou CY, Chang JC, Hsu TY, Kuo HC, Liu CA, et al. Gender-dependent effect of GSTM1 genotype on childhood asthma associated with prenatal tobacco smoke exposure. Biomed Res Int. 2014:2014:769452.

38. Dillon MA, Harris B, Hernandez ML, Zou B, Reed W, Bromberg PA, et al. Enhancement of systemic and sputum granulocyte response to inhaled endotoxin in people with the GSTM1 null genotype. Occup Environ Med. 2011;68(10):783-5.

39. Jeronimo C, Varzim G, Henrique R, Oliveira J, Bento MJ, Silva C, et al. $1105 \mathrm{~V}$ polymorphism and promoter methylation of the GSTP1 gene in prostate adenocarcinoma. Cancer Epidemiol Biomarkers Prev. 2002;11(5):445-50.

40. Ryberg D, Skaug V, Hewer A, Phillips DH, Harries LW, Wolf CR, et al. Genotypes of glutathione transferase $\mathrm{M} 1$ and $\mathrm{P} 1$ and their significance for lung DNA adduct levels and cancer risk. Carcinogenesis. 1997;18(7):1285-9.

41. De Roos AJ, Rothman N, Inskip PD, Linet MS, Shapiro WR, Selker RG, et al. Genetic polymorphisms in GSTM1, -P1, -T1, and CYP2E1 and the risk of adult brain tumors. Cancer Epidemiol Biomarkers Prev. 2003:12(1):14-22.

42. Nasr AS, Sami RM, Ibrahim NY, Darwish DO. Glutathione $S$ transferase (GSTP 1, GSTM 1, and GSTT 1) gene polymorphisms in Egyptian patients with acute myeloid leukemia. Indian J Cancer. 2015;52(4):490-5.

43. Al-Dayel F, Al-Rasheed M, Ibrahim M, Bu R, Bavi P, Abubaker J, et al. Polymorphisms of drug-metabolizing enzymes CYP1A1, GSTT and GSTP contribute to the development of diffuse large B-cell lymphoma risk in the Saudi Arabian population. Leuk Lymphoma. 2008;49(1):122-9.

44. Garcia-Gonzalez MA, Quintero E, Bujanda L, Nicolas D, Benito R, Strunk M, et al. Relevance of GSTM1, GSTT1, and GSTP1 gene polymorphisms to gastric cancer susceptibility and phenotype. Mutagenesis. 2012;27(6):771-7.

45. Wang ZY, Zhou J, Luo L, Huang YL, Dong PD. Predictive role of glutathioneS-transferase gene polymorphisms in the survival of gastric cancer cases. Asian Pac J Cancer Prev. 2012;13(4):1515-8.

46. Li CG, Zhao ZM, Hu MG, Liu R. Predictive role of glutathione-S-transferase gene polymorphisms in risk and prognosis of hepatocellular carcinoma. Asian Pac J Cancer Prev. 2012:13(7):3247-52.

47. Masoudi M, Saadat I, Omidvari S, Saadat M. Genetic polymorphisms of GSTO2, GSTM1, and GSTT1 and risk of gastric cancer. Mol Biol Rep. 2009, 36(4):781-4.

48. Muniesa CA, Gonzalez-Freire M, Santiago C, Lao Jl, Buxens A, Rubio JC, et al. World-class performance in lightweight rowing: is it genetically influenced? A comparison with cyclists, runners and non-athletes. Br J Sports Med. 2010; 44(12):898-901.

49. Ruiz JR, Arteta D, Buxens A, Artieda M, Gomez-Gallego F, Santiago C, et al. Can we identify a power-oriented polygenic profile? J Appl Physiol (1985). 2010 Mar; 108(3):561-566.

50. Zweig MH, Campbell G. Receiver-operating characteristic (ROC) plots: a fundamental evaluation tool in clinical medicine. Clin Chem. 1993;39(4):561-77.

51. Pitsiladis $Y$, Wang G, Wolfarth B, Scott R, Fuku N, Mikami E, et al. Genomics of elite sporting performance: what little we know and necessary advances. Br J Sports Med. 2013:47(9):550-5.

52. Massidda M, Scorcu M, Calo CM. New genetic model for predicting phenotype traits in sports. Int J Sports Physiol Perform. 2014;9(3):554-60

53. Shahmoradi S, Ahmadalipour A, Salehi M. Evaluation of ACE gene I/D polymorphism in Iranian elite athletes. Adv Biomed Res. 2014;3:207.

54. Papadimitriou ID, Lockey SJ, Voisin S, Herbert AJ, Garton F, Houweling PJ, et al. No association between ACTN3 R577X and ACE I/D polymorphisms and endurance running times in 698 Caucasian athletes. BMC Genomics. 2018;19(1):13.

55. Tong TK, Kong Z, Lin H, He Y, Lippi G, Shi Q, et al. Effects of 12-week endurance training at natural low altitude on the blood redox homeostasis of professional adolescent athletes: a quasi-experimental field trial. Oxid Med Cell Longev. 2016;2016:4848015.

56. Lewis NA, Towey C, Bruinvels G, Howatson G, Pedlar CR. Effects of exercise on alterations in redox homeostasis in elite male and female endurance athletes using a clinical point-of-care test. Appl Physiol Nutr Metab. 2016; 41(10):1026-32

57. Lewis NA, Howatson G, Morton K, Hill J, Pedlar CR. Alterations in redox homeostasis in the elite endurance athlete. Sports Med. 2015;45(3):379-409.

58. Barbosa de Queiroz K, Honorato-Sampaio K, Rossoni Junior JV, Andrade Leal $D$, Pinto $A B$, Kappes-Becker $L$, et al. Physical activity prevents alterations in mitochondrial ultrastructure and glucometabolic parameters in a high-sugar diet model. PLoS One. 2017;12(2):e0172103.

59. Fernandez JM, Da Silva-Grigoletto ME, Gomez-Puerto JR, Viana-Montaner BH, Tasset-Cuevas I, Tunez I, et al. A dose of fructose induces oxidative stress during endurance and strength exercise. J Sports Sci. 2009;27(12): 1323-34.

60. Venkatraman JT, Feng X, Pendergast D. Effects of dietary fat and endurance exercise on plasma cortisol, prostaglandin E2, interferon-gamma and lipid peroxides in runners. J Am Coll Nutr. 2001;20(5):529-36.

61. Michalczyk M, Czuba M, Zydek G, Zajac A, Langfort J. Dietary recommendations for cyclists during altitude training. Nutrients. 2016; 18:8(6).

62. Leonardo-Mendonca RC, Concepcion-Huertas M, Guerra-Hernandez E, Zabala M, Escames G, Acuna-Castroviejo D. Redox status and antioxidant response in professional cyclists during training. Eur J Sport Sci. 2014;14(8): 830-8.

63. Quindry JC, McAnulty SR, Hudson MB, Hosick P, Dumke C, McAnulty LS, et al. Oral quercetin supplementation and blood oxidative capacity in response to ultramarathon competition. Int I Sport Nutr Exerc Metab. 2008; 18(6):601-16.

64. Machefer G, Groussard C, Zouhal H, Vincent S, Youssef H, Faure H, et al. Nutritional and plasmatic antioxidant vitamins status of ultra endurance athletes. J Am Coll Nutr. 2007;26(4):311-6.

65. Al-Khelaifi F, Diboun I, Donati F, Botre F, Alsayrafi M, Georgakopoulos C, et al. A pilot study comparing the metabolic profiles of elite-level athletes from different sporting disciplines. Sports Med Open. 2018;4(1):2.

66. Ahmetov II, Naumov VA, Donnikov AE, Maciejewska-Karlowska A, Kostryukova ES, Larin AK, et al. SOD2 gene polymorphism and muscle damage markers in elite athletes. Free Radic Res. 2014;48(8):948-55.

67. Oh S, Komine S, Warabi E, Akiyama K, Ishii A, Ishige K, et al. Nuclear factor (erythroid derived 2)-like 2 activation increases exercise endurance capacity via redox modulation in skeletal muscles. Sci Rep. 2017;7(1):12902

68. Costa AM, Breitenfeld L, Silva AJ, Pereira A, Izquierdo M, Marques MC. Genetic inheritance effects on endurance and muscle strength: an update. Sports Med. 2012;42(6):449-58.

69. Akimoto AK, Miranda-Vilela AL, Alves PC, Pereira LC, Lordelo GS, Hiragi Cde $\mathrm{O}$, et al. Evaluation of gene polymorphisms in exercise-induced oxidative stress and damage. Free Radic Res. 2010;44(3):322-31.

70. Mahoney DJ, Parise G, Melov S, Safdar A, Tarnopolsky MA. Analysis of global mRNA expression in human skeletal muscle during recovery from endurance exercise. Faseb j. 2005;19(11):1498-500.

71. Jenkins NT, Landers RQ, Prior SJ, Soni N, Spangenburg EE, Hagberg JM. Effects of acute and chronic endurance exercise on intracellular nitric oxide and superoxide in circulating CD34(+) and CD34(-) cells. J Appl Physiol (1985). 2011 Sep;111(3):929-37.

72. Neubauer O, Sabapathy S, Lazarus R, Jowett JB, Desbrow B, Peake JM, et al. Transcriptome analysis of neutrophils after endurance exercise reveals novel signaling mechanisms in the immune response to physiological stress. J Appl Physiol (1985). 2013 Jun 15;114(12):1677-88.

73. Stepanova M, Hossain N, Afendy A, Perry K, Goodman ZD, Baranova A, et al. Hepatic gene expression of Caucasian and African-American patients with obesity-related non-alcoholic fatty liver disease. Obes Surg. 2010;20(5):640-50.

74. Rana SV, Kamboj JK, Sharma SK, Ola RP, Sinha SK, Singh K. Antioxidant status and GST gene polymorphisms in antitubercular treatment-induced hepatotoxicity patients. Hepatol Int. 2013;7(3):876-82.

75. McGarry DJ, Chakravarty P, Wolf CR, Henderson CJ. Altered protein Sglutathionylation identifies a potential mechanism of resistance to acetaminophen-induced hepatotoxicity. J Pharmacol Exp Ther. 2015;355(2):137-44.

76. Pourahmad J, Eskandari MR, Nosrati M, Kobarfard F, Khajeamiri AR. Involvement of mitochondria//ysosomal toxic cross-talk in ecstasy induced liver toxicity under hyperthermic condition. Eur J Pharmacol. 2010;643(2-3):162-9.

77. Ganesan S, Tekwani BL, Sahu R, Tripathi LM, Walker LA. Cytochrome P(450)dependent toxic effects of primaquine on human erythrocytes. Toxicol Appl Pharmacol. 2009;241(1):14-22. 
78. Tong TK, Kong Z, Lin H, Lippi G, Zhang H, Nie J. Serum oxidant and antioxidant status following an all-out 21-km run in adolescent runners undergoing professional training--a one-year prospective trial. Int J Mol Sci. 2013:14(7):15167-78.

79. Cordova A, Sureda A, Albina ML, Linares V, Belles M, Sanchez DJ. Oxidative stress markers after a race in professional cyclists. Int I Sport Nutr Exerc Metab. 2015;25(2):171-8.

\section{Publisher's Note}

Springer Nature remains neutral with regard to jurisdictional claims in published maps and institutional affiliations.

Submit your manuscript to a SpringerOpen ${ }^{\circ}$ journal and benefit from:

- Convenient online submission

- Rigorous peer review

- Open access: articles freely available online

- High visibility within the field

- Retaining the copyright to your article

Submit your next manuscript at $\boldsymbol{\wedge}$ springeropen.com 